\title{
Detection of specific Mycoplasma conjunctivae antibodies in the sera of sheep with infectious keratoconjunctivitis
}

\author{
Luc Belloy $^{\mathrm{a}}$, Marco Giacometti ${ }^{\mathrm{b}}$, El-Mostafa ABDO ${ }^{\mathrm{a}}$, \\ Jacques NICOLET ${ }^{\mathrm{a}}$, Margrit KRAWINKLER ${ }^{\mathrm{a}}$, Martin JANOVSKY ${ }^{\mathrm{c}}$, \\ Urs BRUDERER $^{\mathrm{d}}$, Joachim FREY ${ }^{\mathrm{a} *}$ \\ a Institute for Veterinary Bacteriology, University of Berne, \\ Länggass-Strasse 122, 3012 Bern, Switzerland \\ ${ }^{\mathrm{b}}$ Wildvet Projects, 7605 Stampa, Switzerland \\ ${ }^{\mathrm{c}}$ Center for Fish and Wildlife Health, Institute of Animal Pathology, University of Berne, \\ Länggass-Strasse 122, 3012 Bern, Switzerland \\ ${ }^{\mathrm{d}}$ Dr. Bommeli AG, Stationsstrasse 12, 3097 Liebefeld, Switzerland
}

(Received 6 November 2000; accepted 18 December 2000)

\begin{abstract}
The serological cross reactions between Mycoplasma conjunctivae, the etiological agent of infectious keratoconjunctivitis (IKC), and the antigenetically and phylogenetically closely related Mycoplasma ovipneumoniae, which is often found in sheep, were analysed. Cross reacting antigens were identified using sera from sheep with IKC and from sheep of herds known to be free of IKC, as well as rabbit hyperimmune serum specific to the two Mycoplasma species. Cross reactions were predominantly due to the strongly antigenic proteins of $42 \mathrm{kDa}$ and $83 \mathrm{kDa}$. Serospecific antigens of $M$. conjunctivae could be separated from cross-reacting antigens by the extraction of Tween 20-soluble membrane proteins. The Tween 20 -extracted proteins of the M. conjunctivae strain $\mathrm{HRC} / 581^{\mathrm{T}}$ were used for the development of an indirect ELISA test. This ELISA test was shown to be a useful serological method for the diagnosis of $M$. conjunctivae infections and to identify infected sheep herds.
\end{abstract}

Mycoplasma conjunctivae / serodiagnosis / specific antigens / ELISA / Mycoplasma ovipneumoniae

Résumé - Détection d'anticorps spécifiques de Mycoplasma conjunctivae dans les sérums de moutons atteints de kérato-conjonctivite infectieuse. Les réactions sérologiques croisées entre Mycoplasma conjunctivae, l'agent étiologique de la kérato-conjonctivite infectieuse (KCI), et Mycoplasma ovipneumoniae, qui lui est antigéniquement et phylogénétiquement le plus proche et qui est souvent présent chez le mouton, ont été analysées. Des sérums provenant de moutons atteints de KCI et

* Correspondence and reprints

Tel.: (41) 31631 2484; fax: (41) 31631 2634; e-mail: joachim.frey@ vbi.unibe.ch 
de moutons issus de troupeaux exempts de KCI, ainsi que des sérums hyperimmuns de lapin spécifiques pour les deux espèces de mycoplasmes, ont permis l'identification des antigènes impliqués dans les réactions croisées. Les réactions croisées sont principalement dues aux protéines fortement antigéniques de $42 \mathrm{kDa}$ et $83 \mathrm{kDa}$. Les antigènes sérospécifiques de Mycoplasma conjunctivae peuvent être séparés des antigènes provoquant une réaction croisée par une extraction des protéines membranaires au Tween 20. Les protéines de Mycoplasma conjunctivae $\mathrm{HRC} / 581^{\mathrm{T}}$ extraites par le détergent Tween 20 ont été utilisées dans le développement d'un ELISA indirect. Cet ELISA s'est avéré être une méthode sérologique utile pour le diagnostique des infections dues à Mycoplasma conjunctivae ainsi que pour identifier les troupeaux de moutons infectés.

Mycoplasma conjunctivae / sérodiagnostic / antigènes spécifiques / ELISA / Mycoplasma ovipneumoniae

\section{INTRODUCTION}

Infectious keratoconjunctivitis (IKC), commonly known as pink-eye, is a contagious disease of domestic ruminants as well as wild caprinae species such as Alpine chamois (Rupicapra rupicapra rupicapra), Alpine ibex (Capra ibex ibex), Himalayan thar (Hemitragus jemlahicus), and European muflon (Ovis orientalis musimon) [12]. IKC is widespread in domestic sheep and goats [17], and in wild Caprinae where it is reported in Europe and New Zealand. The term IKC is used to describe a clinical condition which can apparently not always be ascribed to the same infectious agent [11]. Mycoplasma conjunctivae has often been involved as the causative agent of IKC in both domestic $[16,18]$ and wild ruminants $[7,9,13]$, but its prevalence is not well known in most countries. This may be due to the lack of techniques for the detection of $M$. conjunctivae infections. The classical method for the diagnosis of $M$. conjunctivae infection is the culture and subsequent identification of colonies of mycoplasmas by immunological methods. However, this method is cumbersome and requires specialised technical experience. Recently, a PCR method based on the 16 S rRNA gene, for the detection and identification of the agent from clinical material was described as well as a Western blot technique for the detection of $M$. conjunctivae antibodies in infected animals $[5,7]$. In contrast, no method is available for the rapid detection of specific $M$. conjunctivae antibodies in sera.

An accurate method for serodetection, however, is currently needed for advancement in research with regard to the epidemiology of IKC in small ruminants. This is particularly important in the context of M. ovipneumoniae which is very often isolated from sheep with respiratory disease [4] and which is phenotypically and antigenetically the most closely related mycoplasma species to $M$. conjunctivae $[5,15]$. The hypothesis was made that the sheep population was acting as a reservoir of $M$. conjunctivae infections in Switzerland [8], but this role is still unproved. In the present study we analysed the specificity of serological reactions to a Tween 20-extracted membrane fraction of $M$. conjunctivae proteins and showed its use as an antigen in an ELISA test for the serodiagnosis of IKC.

\section{MATERIALS AND METHODS}

\subsection{Animals and samples}

The study was performed on eight sheep herds in Switzerland. Blood samples were collected from the jugular vein, blood was centrifuged and serum stored at $-20{ }^{\circ} \mathrm{C}$ until analysis.

Samples of negative controls were collected from sheep of two herds (A and B) which had had no IKC history more than 
three years. These herds had no contact with sheep from other herds all year round, including during summer time, and single males were introduced into the herd only sporadically. Herd A amounted to approximately 400 sheep (White Swiss Mountain sheep) and was located in Grisons, a canton in the eastern Swiss Alps. Herd B was smaller (approximately 80 sheep, White Swiss Mountain sheep) and was located in the Bernese plateau.

Samples from six herds (C-H) suspected of being infected with $M$. conjunctivae due to apparent clinical symptoms were collected in three Swiss cantons (Grisons, Bern, Uri). Clinical signs considered for IKC were conjunctival hyperemia, serous as well as mucous lachrymation, eyelid swelling, corneal dulling, and corneal neovascularisation. The percentages of animals with clinical symptoms in these herds are given in Table I. In these herds, $M$. conjunctivae was detected by PCR in the eyes of sheep [7].

To detect $M$. conjunctivae infections we used a nested PCR test based on the $16 \mathrm{~S}$ rRNA gene, performed on eye swabs from behind the third eyelid [7]. Furthermore, a Western blot technique was used to detect M. conjunctivae antibodies from serum [5].

\subsection{Mycoplasma strains and culture conditions}

Mycoplasma conjunctivae type strain $\mathrm{HRC} / 581^{\mathrm{T}}$ and Mycoplasma ovipneumoniae type strain $\mathrm{Y}^{\mathrm{T}}{ }^{\mathrm{T}}$ were grown on standard mycoplasma PPLO broth medium (Difco Laboratories, Detroit, MI, USA) enriched with $20 \%$ horse serum, $2.5 \%$ yeast extract and $1 \%$ glucose [2].

\subsection{Antigen preparation}

M. conjunctivae and M. ovipneumoniae cells from the late exponential phase were harvested by centrifugation at $12000 \times g$ for $20 \mathrm{~min}$, washed three times in TES buffer (10 mM Tris-HCl, $1 \mathrm{mM}$ EDTA, $144 \mathrm{mM} \mathrm{NaCl} \mathrm{pH} 7.5)$, and then concentrated by resuspension in TES buffer corresponding to $1 \%$ of the original culture volume and referred to as the whole cell antigen.

For the preparation of the membrane fraction antigens, the method of Hjerten and Johansson [10] was used, after a slight modification. $M$. conjunctivae cells were harvested by centrifugation and then resuspended in TES buffer at $1 \mathrm{mg}$ (wet cells) $\cdot \mathrm{mL}^{-1}$. Subsequently, Tween 20 was added to a final concentration of $1 \%(\mathrm{~V} / \mathrm{V})$.

Table I. Prevalence of M. conjunctivae seropositive sheep in herds with known IKC.

\begin{tabular}{lcccc}
\hline Herd & $\begin{array}{c}\text { Number of } \\
\text { samples }\end{array}$ & $\begin{array}{c}\text { \% animals } \\
\text { with IKC symptoms }\end{array}$ & $\begin{array}{c}\text { Seropositive } \\
\text { OD } \geq 37 \%\end{array}$ & $\begin{array}{c}\text { Negative } \\
\text { OD }<37 \%\end{array}$ \\
\hline $\mathrm{C}$ & 30 & 41 & $24(80)^{\mathrm{a}}$ & $6(20)$ \\
$\mathrm{D}$ & 9 & 67 & $9(100)$ & 0 \\
$\mathrm{E}$ & 64 & 8 & $38(59)$ & $26(41)$ \\
$\mathrm{F}$ & 56 & 4 & $45(80)$ & $11(20)$ \\
$\mathrm{G}$ & 30 & 45 & $22(73)$ & $8(27)$ \\
$\mathrm{H}$ & 60 & 27 & $42(70)$ & $18(30)$ \\
Total & 249 & $180(72)$ & $69(28)$ \\
\hline
\end{tabular}

${ }^{\text {a }}$ Percentage of the samples are given in brackets. 
The suspension was then incubated at $37{ }^{\circ} \mathrm{C}$ for 90 min with gentle mixing and cleared by ultracentrifugation at $48000 \times g$ at $4{ }^{\circ} \mathrm{C}$ for $60 \mathrm{~min}$. The supernatant was then filtered through low protein binding membrane $(0.2 \mu \mathrm{m})$. This procedure resulted in a fraction of dissolved mycoplasma membrane proteins and was referred to as Tween 20 membrane protein fraction. Protein concentrations were measured by the method of Bradford [3].

\subsection{Preparation of antisera}

The preparation of rabbit hyperimmune antisera against whole cell antigen of $M$. conjunctivae $\left(\mathrm{HRC} / 581^{\mathrm{T}}\right)$ and M. ovipneumoniae $\left(\mathrm{Y} 98^{\mathrm{T}}\right)$ was made by immunisation of rabbits using the technique as described previously [2].

\subsection{Western blotting}

Whole cell antigen or Tween 20 membrane fraction was prepared for separation by SDS polyacrylamide gel electrophoresis (SDS-PAGE) by mixing the concentrated cells or the Tween 20 extract, respectively, with one volume of SDS sample buffer (0.06 M Tris-HCL pH 6.8, 2\% SDS, $10 \%$ Glycerol, 2\% $\beta$-mercaptoethanol, $0.025 \%$ Bromphenol blue) and boiling for $5 \mathrm{~min}$. The antigens were separated by SDS-PAGE on $5-15 \%$ gradient gels as described above, and blotted onto nitro-cellulose membrane with a pore size of $0.2 \mu \mathrm{m}$ (BioRad, Hercules, CA, USA). The membrane was then blocked with milk buffer $(100 \mathrm{mM}$ Tris $\mathrm{HCl}$ pH 7.5, $150 \mathrm{mM} \mathrm{NaCl}, 0.5 \%$ Tween $20,1 \%$ skimmed dry milk) for $1 \mathrm{~h}$ at room temperature (r.t.), dried, and cut into strips. The strips were incubated for $1 \mathrm{~h}$ at r.t. with the sheep serum samples diluted 1:50 in milk buffer and washed three times with TES for $5 \mathrm{~min}$. The strips were then incubated for $1 \mathrm{~h}$ at r.t. with alkaline phosphatase-labelled conjugate, which was diluted in milk buffer.
For the detection of bound antibodies, the following conjugates were used: (i) monoclonal antibody (Mab) to goat/sheep-IgG (Sigma Chemicals, Saint Louis, MO, USA, product \# A-8062) diluted 1:2000, or (ii) polyclonal anti-rabbit IgG antibodies (Kirkegaard and Perry, Gaithersberg, MD, USA, product \# 075-1506) diluted 1:2000. All the strips were washed three times with TES buffer. Colour reaction was initiated by $0.3 \mathrm{mg} \cdot \mathrm{mL}^{-1}$ Nitroblue tetrazolium (NBT) (Roche Diagnostics, Rotkreuz Switzerland, product \# 1585029) plus $0.15 \mathrm{mg}$ 5-Bromo-4chloro-3indolyl phosphate (BCIP) (Roche Diagnostics, product \# 1585:002) in alkaline buffer and stopped with distilled water as described [1].

For the adsorption of sera, Mycoplasma cultures $\left(10^{8}\right.$ cells $\left.\cdot \mathrm{mL}^{-1}\right)$ were washed twice in TES buffer and resuspended in TES to obtain a suspension of $10^{9}$ cells $\cdot \mathrm{mL}^{-1}$. Sera were adsorbed by incubation of serum with $1 / 10$ volume of $10^{9}$ cells $\cdot \mathrm{mL}^{-1}$ suspension of the corresponding Mycoplasma culture for $2 \mathrm{~h}$ at $50{ }^{\circ} \mathrm{C}$ followed by centrifugation at $10000 \times g$ for 15 min to clear the serum.

\subsection{ELISA}

An indirect ELISA method for the detection of specific $M$. conjunctivae antibodies in sheep sera was developed, based on the Tween 20-extracted membrane fraction of M. conjunctivae strain $\mathrm{HRC} / 581^{\mathrm{T}}$. Tween 20 extracts were titrated according to standard methods [14] and plates coated at an optimal concentration of $1.25 \mu \mathrm{g} \cdot \mathrm{mL}^{-1}$.

For the analysis of the sheep sera, serum was diluted $1 / 10$, applied to the plates and analysed using anti-ruminant-IgG (Chekit, "Dr. Bommeli AG", Stationsstrasse 12, Bern-Liebefeld, Switzerland), a monoclonal antibody directed against ruminant IgG conjugate to horseradish peroxidase. The optical densities were measured with a photometer at a wavelength of $405 \mathrm{~nm}$. The value of each sample was expressed as a percentage of a positive reference standard, 
by taking a negative reference serum as the zero value according to approved standardisation methods [14, 19].

\section{RESULTS}

\subsection{Serological specificity of $M$. conjunctivae antigens}

In order to assess the serological specificity of $M$. conjunctivae antigens, we analysed on immunoblots whole cell antigens of a culture of $M$. conjunctivae type strain $\mathrm{HRC} / 581^{\mathrm{T}}$ with rabbit immune serum directed against $M$. ovipneumoniae and also with rabbit immune serum directed against M. conjunctivae (Fig. 1, panel a). Strong serological cross reactions with anti-M. ovipneumoniae rabbit antiserum were observed on immunoblots containing $M$. conjunctivae whole cell antigens in particular with a $83 \mathrm{kDa}$ antigen and to a lesser extent with a $42 \mathrm{kDa}$ antigen (Fig. 1, panel a). Both these antigens belong to the major antigens of $M$. conjunctivae as shown in Figure 1, panel a, stripe c. When serum from sheep that were suffering from IKC was analysed on immunoblots containing whole cell antigens of $M$. conjunctivae the same $83 \mathrm{kDa}$ and $42 \mathrm{kDa}$ antigens exhibited the predominant reactions (Fig. 1, panel b). The Tween 20 membrane protein fraction of $M$. conjunctivae, however, was virtually devoid of the $83 \mathrm{kDa}$ antigen (Fig. 1, panel b). In order to assess further the specificity of the Tween 20 membrane protein fraction, we have analysed sera of eight sheep from the IKC-negative herd $\mathrm{A}$ and the sera of nine sheep from the IKC-positive herd D on immunoblot with either $M$. conjunctivae whole cell antigen or Tween 20-extracted antigens, or M. ovipneumoniae whole cell antigen (Fig. 2). The sera of the IKC-negative herd A exhibited reactions with several proteins and $M$. conjunctivae whole cell antigens, but practically no reactions with antigens of the Tween 20 membrane protein fraction (Fig. 2, panel b). These sera a) b)

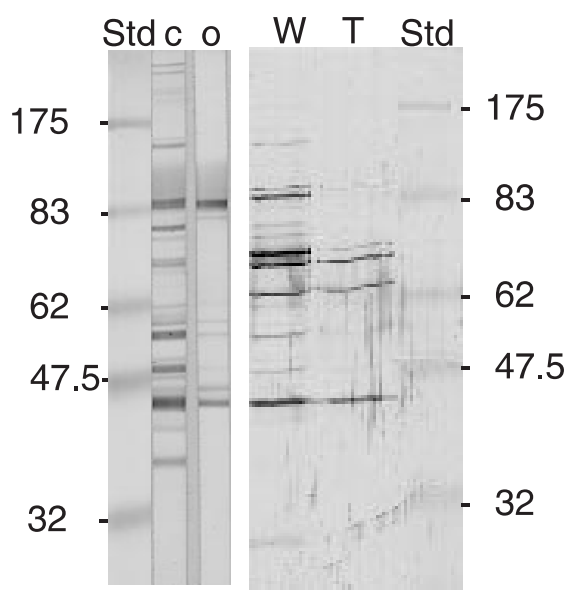

Figure 1. Specificity of $M$. conjunctivae antigens. Panel (a) Immunoblots containing whole cell antigens of $M$. conjunctivae $\mathrm{HRC} / 581^{\mathrm{T}}$ were reacted with rabbit serum directed against $M$. conjunctivae (lane c) and rabbit serum directed against M. ovipneumoniae (lane o). Panel (b) Immunoblot containing whole cell antigens (lane W) and Tween 20 extract antigens (lane T) from $M$. conjunctivae $\mathrm{HRC} / 581^{\mathrm{T}}$ reacted with serum from a sheep with IKC. Std: prestained molecular mass protein standard annotated in kilodaltons $(\mathrm{kDa})$.

also reacted on immunoblots with $M$. ovipneumoniae antigens, indicating infection with the latter. Among the sera from nine sheep of the IKC-positive herd D, all reacted strongly with both whole cell and Tween 20-extracted antigens of $M$. conjunctivae, while only six of these sera reacted strongly with $M$. ovipneumoniae, indicating that these animals were infected with both $M$. conjunctivae and M. ovipneumoniae (Fig. 2). The remaining three sera (animal \# 270, animal \# 271 and animal \# 272) only showed a weak reaction with $M$. ovipneumoniae antigens which could be due to cross reactions (Fig. 2). This could indicate that these animals were only infected with $M$. conjunctivae. These observations were further 



Figure 2. Serological cross reaction between antigens of $M$. conjunctivae and $M$. ovipneumoniae. Sera from sheep of an IKC-negative herd (animals 224-260) and sera of sheep from an IKC-positive herd (animals 263-272) were analysed on immunoblot strips containing either whole cell antigens of M. conjunctivae $\mathrm{HRC} / 581^{\mathrm{T}}$ (panel (a)) or Tween 20-extracted membrane proteins of $M$. conjunctivae (panel (b)), or whole cell antigen of M. ovipneumoniae $\mathrm{Y}^{\mathrm{T}}{ }^{\mathrm{T}}$ (panel (c)). Std: pre-stained molecular mass protein standard annotated in $\mathrm{kDa}$. The ELISA values of the corresponding sera are given below the immunoblot strips of panel (b). 
confirmed by adsorption experiments as shown in Figure 3. The serum from sheep \# 263, which was apparently seropositive for both $M$. conjunctivae and M. ovipneumoniae (Fig. 3 lane $\mathrm{x}$, non-adsorbed), was adsorbed either with $M$. conjunctivae (Fig. 3 lane c) or M. ovipneumoniae (lane o) and then reacted on immunoblots containing whole cell antigens of either $M$. conjunctivae (Fig. 3, M. con) or M. ovipneumoniae (Fig. 3, M. ovi). This serum lost reactivity when adsorbed with the homologous antigen prior to blotting on both $M$. conjunctivae and $M$. ovipneumoniae immunoblots, but retained its activity on both blots when adsorbed with heterologous antigen. This gave further evidence that this animal had a double infection with $M$. conjunctivae and with $M$. ovipneumoniae. In contrast, the serum from animal \# 253 lost reactivity to $M$. conjunctivae blots after both homologous and heterologous adsorption (Fig. 3, animal \# 253), and only retained reactivity to $M$. ovipneumoniae antigens after heterologous adsorption with $M$. conjunctivae. Animal \# 253 is hence assumed to be seropositive for M. ovipneumoniae only.

\subsection{Tween 20 membrane extract ELISA}

In order to get a rational and efficient method for the serodiagnosis of a large number of animals in the context of epidemiological studies and the monitoring of IKC in sheep herds, we developed an indirect ELISA using microtitre plates coated with Tween 20 membrane protein extract of M. conjunctivae. Titration experiments showed that an optimal protein concentration of $6.25 \mu \mathrm{g} \cdot \mathrm{mL}^{-1}$ produced maximum resolution of a positive reference serum from a sheep of an IKC-infected herd used as $100 \%$ value.

The eight sera from IKC-negative sheep that were analysed in detail on immunoblots (Fig. 2) revealed no antibodies against $M$. conjunctivae Tween 20-extract membrane



Figure 3. Adsorption experiment of sera from animals double infected with $M$. conjunctivae and M. ovipneumoniae. Serum from sheep \# 263 which was apparently infected by both $M$. conjunctivae and M. ovipneumoniae (left part) and serum from sheep \# 253 which was from a herd free of IKC but apparently infected by M. ovipneumoniae were used. The immunoblots contained either full antigens of $M$. conjunctivae ( $M$. con) or full antigens of $M$. ovipneumoniae ( $M$. ovi). The immunoblot stripes were incubated with sera that were non-adsorbed (lane $\mathrm{x}$ ), or adsorbed with $M$. ovipneumoniae full antigen (lane o), or adsorbed with M. conjunctivae full antigen (lane c). The molecular mass standard for proteins (Std) is given in $\mathrm{kDa}$.

protein. Nevertheless, they were positive for M. ovipneumoniae, and produced ELISA values ranging from $2 \%$ to $37 \%$ relative to the standard serum $(100 \%)$ with a mean value of $24.4 \%$ which must be considered as non-specific reactions of the ELISA. In contrast, the nine sera from IKC-positive sheep that exhibited specific reaction in the immunoblot analysis (Fig. 2) showed ELISA values ranging from $55 \%$ to $405 \%$ relative to the standard serum (100\%) with a mean value of $159 \%$. These initial analyses revealed good specificity and sensitivity of the ELISA based on Tween 20-extracted membrane proteins. 
In order to validate the ELISA test, sera from 87 sheep of IKC-negative herds A and $\mathrm{B}$ and 249 sera from IKC-positive herds C, $\mathrm{D}, \mathrm{E}, \mathrm{F}, \mathrm{G}$ and $\mathrm{H}$ were analysed by the ELISA (Tab. I). As shown in Figure 4, the sera from sheep of herds devoid of IKC showed ELISA titres averaged around 10\% with a mean value $\overline{\mathrm{x}}=8.3 \%$ and a standard deviation $\sigma \mathrm{n}-1=9.5 \%$. The resulting cutoff value for negative results of the ELISA test was set at $\bar{x}+3(\sigma n-1)=37 \%$, as indicated in Figure 4. The sera from sheep originating from herds with IKC clearly showed elevated ELISA titres reacting up to $400 \%$ (data not shown). In the individual herd the percentage of sheep with a positive ELISA titre $\geq 37 \%$ ranged between $59 \%$ and $100 \%$ of the animals tested. The animals of these herds which revealed ELISA titres below the cut-off value and hence were considered to be sero-negatives, ranged between 0 and $41 \%$ with an average of $28 \%$. It has to be noted that in herds where only few animals showed clinical symptoms, a lower seroprevalence was measured (Tab. I).

\section{DISCUSSION}

Serodiagnosis of IKC by an accurate and rational method such as ELISA will play a central role in control programmes of $M$. conjunctivae infection in the domestic sheep population and in preventing transmission of the disease to other animals, in particular wild caprinae species [6]. One of the major problems underlining the serological detection of mycoplasmal infection in ruminants in general is the high antigenic similarity between related Mycoplasma species. These similarities lead to strong serological cross reactions which often hinder an accurate serological diagnosis of the infection. Infection of domestic sheep and wild caprinae with $M$. conjunctivae was shown to induce a strong humoral response which can be detected by immunoblot analysis through the presence of seroreactive proteins of molecular masses of 175, 83, 68, 60, 50, 42, 36 and $33 \mathrm{kDa}[5,9]$. However, serological cross reactions between $M$. conjunctivae and M. ovipneumoniae and Mycoplasma

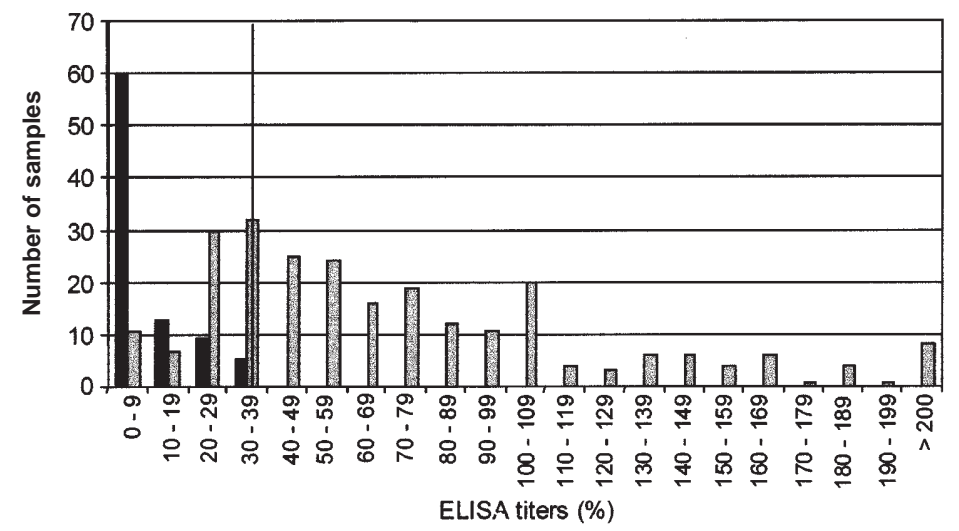

Figure 4. Distribution of ELISA from sheep originating of herds free from IKC and herds with known IKC infections. The bars represent the number of sheep corresponding to the range of ELISA indicated on the $x$-axis. ELISA are given in \% values of a standard serum which was chosen as $100 \%$. Black bars represent sheep from the two herds known to be without IKC for a long period. Grey bars represent the sheep from the herds where clinical symptoms of IKC have been diagnosed. The dark line represents the cut-off value for negative. 
bovoculi have been reported [5]. Based on the immunoblot analysis of full antigen preparations of $M$. conjunctivae we have shown in this work that these cross reactions are mainly due to cross-reacting antigens of $83 \mathrm{kDa}$ and $42 \mathrm{kDa}$ of $M$. conjunctivae which react with anti-M. ovipneumoniae hyperimmune antiserum and with serum from sheep which were seropositive for M. ovipneumoniae. Extraction of membrane proteins of $M$. conjunctivae using the Tween 20 method [10] resulted in a protein fraction which was shown to be antigenetically specific for $M$. conjunctivae. We used these results to establish an ELISA which was shown to be a specific and sensitive test for the serological detection of $M$. conjunctivae infections in sheep. Validation of the method by analysis of a large number of sheep from herds known to be devoid of $M$. conjunctivae infections, but among which certain sheep revealed antibodies to M. ovipneumoniae, showed a good specificity. No individuals produced ELISA titres that were above the cut-off value in the two IKC-free herds. In all of the six herds where IKC was diagnosed based on clinical symptoms and identification of $M$. conjunctivae in the eyes, a significant part of the sheep population (72\% of all animals from these herds) showed positive ELISA titres ( $\geq 37 \%$ of the positive control standard). These titres are considered clearly positive for $M$. conjunctivae infection (Fig. 4). Only a minority (28\% of the animals) showed ELISA titres below the cut-off value and were considered seronegative. These animals represented either noninfected individuals, or animals at a very early stage of infection. However, the herd with the lowest percentage of seropositive animals still revealed to have more than half of the population $(59 \%)$ to be seropositives (Tab. I). In this herd, animals from supposedly IKC negative herds have been introduced at a moment when the infectious stage of the disease must have levelled off. Hence, herd infection by $M$. conjunctivae could clearly be diagnosed by ELISA in all six sheep herds (Tab. I) and reflected IKCinfected sheep as diagnosed in these herds.

We therefore suggest the Tween 20 extract-based $M$. conjunctivae ELISA as a valuable serological test for herd screening of IKC in the sheep population.

\section{ACKNOWLEDGEMENTS}

We are grateful to P. Ratti, K. Jörger, P. Odermatt, R. Oswald, P. Boss, N. Coretti, T. Hummel, M. Zimmermann, A. Giovanoli, P. Juesy, M. Zuber, P. Burri, and P. Weber for their support. This research project was supported by the Fund for Research on Infectious Keratoconjunctivitis, Chur, Switzerland; the Swiss Federal Office for Environment, Forest and Landscape, Bern; and the Research Fund of the Institute for Veterinary Bacteriology, Bern. It is part of the COST Action 826 on ruminant's mycoplasmoses.

\section{REFERENCES}

[1] Ausubel F.M., Brent R., Kingston R.E., Moore D.D., Seidman J.G., Smith J.A., Struhl K., Current protocols in molecular biology, John Wiley \& Sons, New York, N.Y., 1999.

[2] Bannerman E.S., Nicolet J., Isolation and identification of porcine Mycoplasma in Switzerland, Schweiz. Arch. Tierheilkd. 113 (1971) 697-710.

[3] Bradford M.M., A rapid and sensitive method for the quantitation of microgram quantities of protein utilizing the principle of protein-dye binding, Anal. Biochem. 72 (1976) 248-254.

[4] Davies D.H., Aetiology of pneumonias in young sheep, Prog. Vet. Microbiol. Immunol. 1 (1995) 229-248.

[5] Degiorgis M.P., Abdo E.-M., Nicolet J., Frey J., Mayer D., Giacometti M., Immune responses to Mycoplasma conjunctivae in Alpine ibex, Alpine chamois, and domestic sheep in Switzerland, J. Wildl. Dis. 36 (2000) 265-271.

[6] Giacometti M., Nicolet J., Frey J., Krawinkler M., Meier W., Welle M., Johansson K.E., Degiorgis M.P., Susceptibility of Alpine ibex to conjunctivitis caused by inoculation of a sheep-strain of Mycoplasma conjunctivae., Vet. Microbiol. 61 (1998) 279-288.

[7] Giacometti M., Nicolet J., Johansson K.E., Naglic T., Degiorgis M.P., Frey J., Detection and identification of Mycoplasma conjunctivae in infectious keratoconjunctivitis by PCR based on the 
16S rRNA gene, Zentralbl. Veterinaermed. B 46 (1999) 173-180.

[8] Giacometti M., Frey J., Janovsky M., Krawinkler M., Schlatter Y., Belloy L., Fatzer R., Nicolet J., Infectious keratoconjunctivitis (in german), Schweiz. Arch. Tierheilkd. 142 (2000) 235-240.

[9] Grattarola C., Frey J., Abdo E.-M., Orusa R., Nicolet J., Giacometti M., Mycoplasma conjunctivae infections in chamois and ibexes affected with infectious keratoconjunctivitis in the Italian Alps, Vet. Rec. 145 (1999) 588-589.

[10] Johansson K.E., Hjerten S., Localization of the Tween 20-soluble membrane proteins of Acholeplasma laidlawii by crossed immunoelectrophoresis, J. Mol. Biol. 86 (1974) 341-348

[11] Jones G.E., Infectious keratoconjunctivitis, in: Martin W.B., Aitken I.D. (Eds.), Diseases of sheep, Blackwell Scientific Publications, London, 1991, pp. 280-283.

[12] Mayer D., Nicolet J., Giacometti M., Schmitt M., Wahli T., Meier W., Isolation of Mycoplasma conjunctivae from conjunctival swabs of Alpine ibex (Capra ibex ibex) affected with infectious keratoconjunctivitis, J. Vet. Med. B 43 (1996) 155-161.

[13] Nicolet J., Freundt E.A., Isolation of Mycoplasma conjunctivae from chamois and sheep affected with keratoconjunctivitis, Zentralbl. Veterinaermed. B 22 (1975) 302-307.
[14] Nicolet J., Martel J.L., ELISA in large animals, in: Tully J.G., Razin S. (Eds.), Molecular and diagnostic procedures in mycoplasmology, Vol. II, Academic Press AP, 1996, pp. 105-113.

[15] Pettersson B., Uhlen M., Johansson K.E., Phylogeny of some mycoplasmas from ruminants based on 16S rRNA sequences and definition of a new cluster within the hominis group, Int. J. Syst. Bact. 46 (1996) 1093-1098.

[16] Trotter S.L., Franklin R.M., Baas E.J., Barile M.F., Epidemic caprine keratoconjunctivitis: experimentally induced disease with a pure culture of Mycoplasma conjunctivae, Infect. Immun. 18 (1977) 816-822.

[17] van Halderen A., Henton M.M., Moraxella spp. infections, in: Coetzer J.A.W., Thomson G.R., Tustin R.C. (Eds.), Infectious diseases of livestock with special reference to Southern Africa Oxford University Press, Cape Town, Oxford, New York, 1994, pp. 1033-1037.

[18] van Halderen A., Vanrensburg W.J.J., Geyer A., Vorster J.H., The Identification of Mycoplasma conjunctivae as an aetiological agent of infectious keratoconjunctivitis of sheep in South Africa, Onderstepoort. J. Vet. Res. 61 (1994) 231237.

[19] Wright P.F., Nilsson E., Van Rooij E.M., Lelenta M., Jeggo M.H., Standardisation and validation of enzyme-linked immunosorbent assay techniques for the detection of antibody in infectious disease diagnosis, Rev. Sci. Tech. Off. Int. Epizoot. 12 (1993) 435-450. 